\title{
Blockchain: Application and Utilization in Higher Education
}

\author{
Jeffrey Lindenmoyer \\ The University of Texas at Tyler \\ Mary Fischer \\ The University of Texas at Tyler
}

This research examines Blockchain and how it can be utilized in higher education. Before exploring how blockchain can be used in higher education, one must understand just how blockchain is formed, how it accumulates information and its attributes both good and bad. To appreciate how blockchain functions, its use in other industries and applications are explored. Based upon blockchain utilization, a discussion of how it can be applied to higher education is explored and discussed.

Keywords: Higher Education, Blockchain, Student Records, Digital Systems

\section{INTRODUCTION}

Blockchain is exactly what its name implies; a series of blocks connected in a chain, but it is far more complex as a recent global survey found $80 \%$ of those who have heard of blockchain report they do not understand what it entails (Hileman and Rauchs, 2017). Blockchain is a distributed record of transactions. Each block is composed of separate transactions batched together to form a continuous chain in a data set. Blockchain has been referred to as a technological breakthrough potentially as important as the internet (Sharples and Dominique, 2016; Pelletier, 2018). Satoshi Nakamoto (2008), whose identity is still unknown, introduced blockchain as part of his whitepaper for a new method of crypto transaction payments, i.e. bitcoin. The whitepaper's purpose was to introduce an electronic payment system based on cryptographic proof rather than trust, allowing any two parties to transact directly with each other without the need for a third party (Nakamoto, 2008). Blockchain, the backbone of bitcoin, allowed for the decentralized method of payment. Today, blockchain is being utilized for other applications by corporate entities (Pelletier, 2018).

In the past decade, companies have begun utilizing the blockchain technology and implementing it in other uses than cryptocurrencies. For example, Walmart recently released the introductory steps to implement blockchain in their produce logistics process to ensure their fresh foods are free of potential diseases such as E. coli and Salmonella (Smith S., 2018). Another example is Blockcerts created by the Massachusetts Institute of Technology (MIT) and a company called Learning Machine (Pelletier, 2018). Blockcerts uses blockchain to collect certificates issued from selective higher education institutions making them accessible to a user (Grech and Camilleria, 2017). These are only two examples of how blockchain is being utilized in other industries than cryptocurrencies. 
This paper outlines (describes) how blockchain can become a disruptive force to transform higher education classroom record keeping and potentially eliminate a layer of administrative bloat. First, we discuss how blockchain works and how it adds transparency, efficiency to data accumulation. Second is a discussion of how the admission and record keeping function of higher education could be transformed.

Essentially, all applicable information in a specific class would be a part of the blockchain and readily accessible. However, unlike a public blockchain, the higher education blockchain would have private components to comply with certain unique Federal, institutional, and accrediting standards (Sharples and Dominique, 2016). The information on the consortium blockchain would include, but would not be limited to the syllabi, assignments, exams, projects, etc. These materials would serve as the "transactions" on the blockchain and would subsequently be verified and become tamper proof. This would provide the students and other authorized individuals with readily accessible information throughout the student's years of college or schoolwork to build a "profile" with all the student's classwork associated with every class, lab, certificate, or other credits earned or completed.

With blockchain, there would be no need for countless administrators to conduct the admissions and registration record keeping process. Potential students such as high school graduates or other applicants, would add their documents to the blockchain to be verified. All the individual's data, which is private, would be added to their profile and checked off on the basis if it meets certain admission criteria or requirements. Essentially prospective students could view their application to their college of choice like an eager pizza lover watches their Domino's pizza being made and delivered through Domino's online interface. A few colleges and universities such as MIT have begun to experiment with blockchain to verify academic credentials (Pelletier, 2018). This information would be compiled with any other university information the student has and would be readily accessible to them at any time. The main goal of implementing blockchain in higher education is added transparency for the student, academic administrators and professors, while keeping the student's information private, and having the university operate at maximum efficiency.

\section{BLOCKCHAIN PROCESSES AND UTILIZATION}

\section{Blockchain Genesis}

Satoshi Nakamoto in his 2008 white paper claimed, "What is needed is an electronic payment system based on cryptographic proof instead of trust, allowing any two willing parties to transact directly with each other without the need for a trusted third party" (p. 1). Nakamoto eventually went on to create Bitcoin and its technological backbone, blockchain (Nakamoto, 2008).

The main features of blockchain are security, increasing efficiencies, and decreasing costs. Blockchain accomplishes this because data is available in real-time, eliminating intermediaries and the need to record transactions in a single ledger (Jernack, 2018). It accomplishes its high-level of security as being tamper proof, decentralized, trustless, and an openly auditable ledger that can be shared and viewed by all users (Murray, 2018). This differs from the typical "cloud" based storage as instead of having information stored on one computer and accessed by individual computers, blockchain allows all devices to access and use a copy of the ledger or database (Tahmincioglu, 2018).

This transparency is a primary marketable component of blockchain. The ability for anyone to view the blockchain and know that the transactions are $100 \%$ truthful is truly groundbreaking. This potential revolutionary technology accelerated the creation of blockchain and, shortly after the release of Nakamoto's 2008 paper, Bitcoin was officially created with the genesis block (first block in the blockchain) on January 3, 2009 (Zheng, Xie, Dai, Chen, and Wang, 2017; Barber, Boyen, Shi and Uzen, 2012).

\section{Blockchain Basics}

With the creation of the genesis block, the blockchain was officially created. Blocks are then continually added to the genesis block and create a chain of blocks, hence the name, "blockchain." Anything of value can be a transaction, moved and stored securely in the blockchain without a 
centralized control (Wiatt, 2019). Each block holds various types of information, such as the nonce, block version, hash, and the parent's block hash (Zheng et al., 2017). Figure 1 gives a visual representation of the structure of a block and its components. The block version indicates which set of block validation rules that are to be followed (Zheng et al., 2017). A merkle tree root hash is a complete binary tree with a value associated to each node, such that each interior node value is a one-way function of the node values of its subset (aka children) (Szydlo, 2004). The time stamp is the date and time the block was created, and it is given in seconds in universal time since January 1, 1970 (Zheng et al., 2017). The nBits component of the block refers to the target threshold of a valid block hash (Zheng et al., 2017). A nonce is a sequence number of transactions relative to a given source account (Weber et al., 2017). A parent block hash is a 256-bit hash value that is associated with the previous block. In the bottom half of the diagram is a transaction counter, which holds all the transactions associated with the block.

These blocks have a data limit of about $1 \mathrm{MB}$ (Zheng et al., 2017). Thus, another block is created for another group of transactions and the new block is linked to the previous block by its merkle tree root hash and the parent block hash. The merkle tree root hash links the current block to past blocks and the parent block hash contains the hash of the previous block. This "overlap" creates the security of blockchain, as once a block is full, the block's contents are sealed and it becomes incorruptible (Alzacar, 2017; Wiatt, 2019). Figure 2 gives a visual representation of the relationship between previous and future block.

FIGURE 1

\section{STRUCTURE OF A BLOCK AND ITS COMPONENTS}

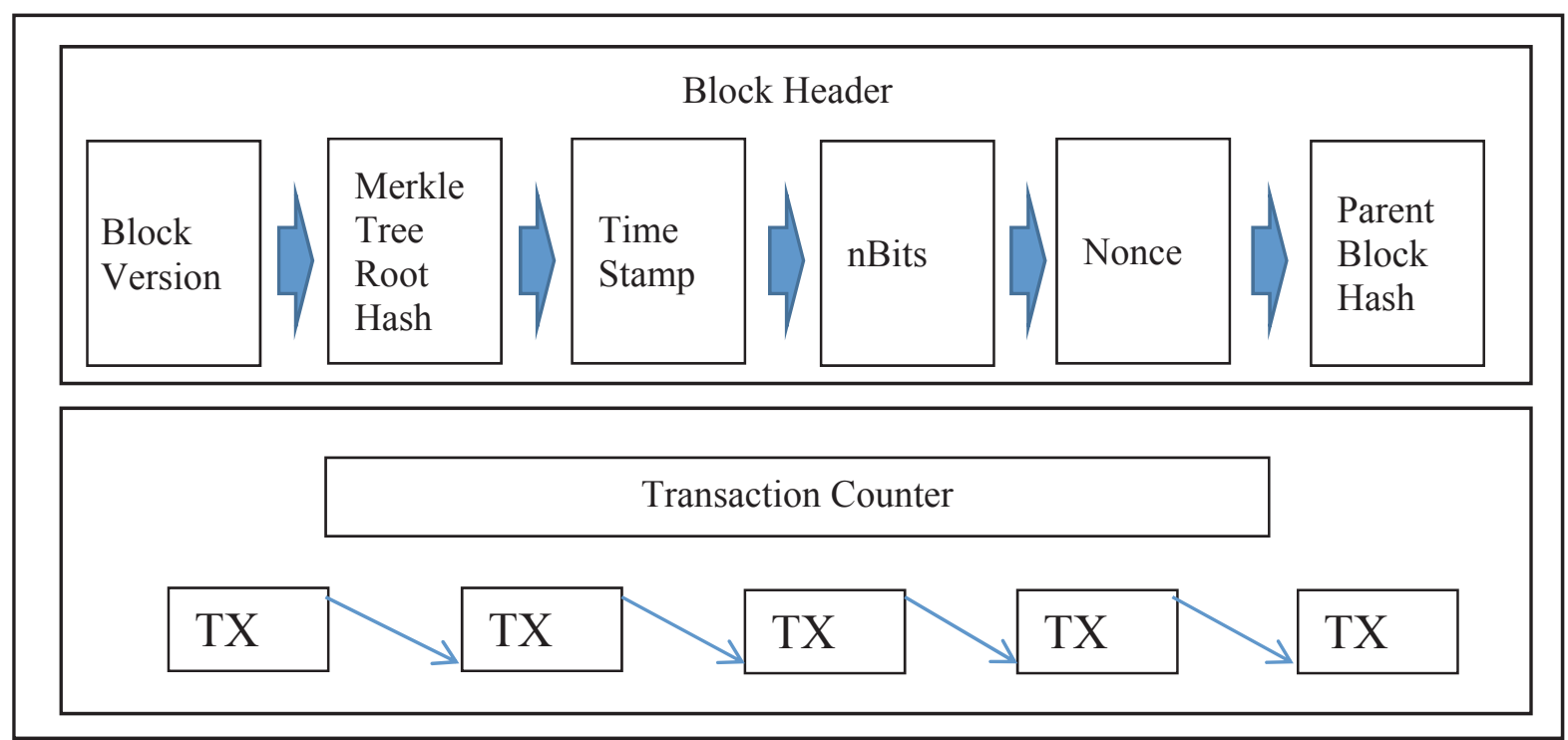

Source: Zheng et al., 2017 


\section{FIGURE 2}

\section{RELATIONSHIP OF PREVIOUS AND FUTURE BLOCKS}

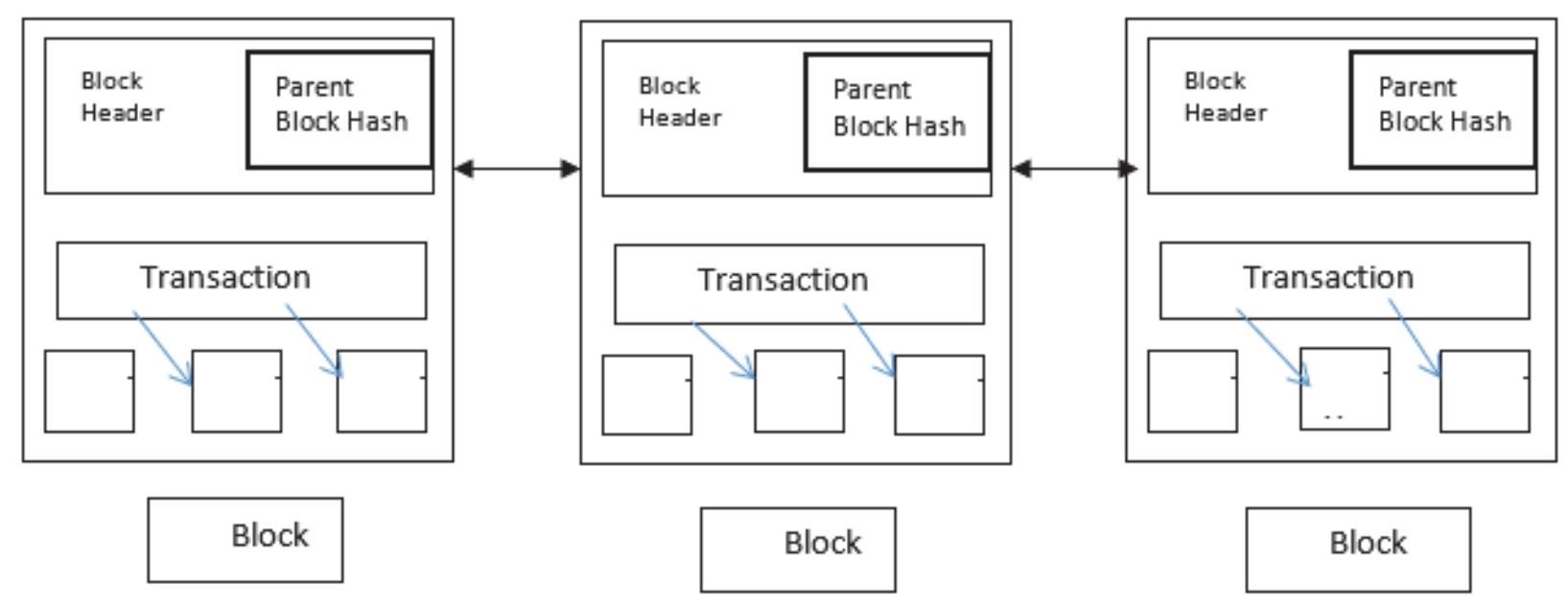

Source: Zheng et al., 2017

As more and more blocks are added to the blockchain, the new blocks are still connected to the genesis block. For instance, the 1000th block in a block chain is linked to the previous block, and the 999th block is linked to the 998th block and so on and so forth. Thus, if someone were to try and corrupt any block or change its components, the entire blockchain would be altered. This makes it nearly impossible to alter or change information, or transactions in a blockchain once they are approved and added to the blockchain. To get added to the blockchain, however, blocks undergo an extensive approval process.

\section{Approval Process}

Confirming a block means that the node has agreed on the authenticity of all transactions within the newly recreated block and the underlying chain (Murray, 2018). Most currently operating blockchains are public permissionless blockchains. Due to Federal compliance criteria, a higher education blockchain must be a mixture of public and private blockchain (consortium blockchain) (Olnes et al., 2017). The public and private blockchains differ in their approval process in a semi-substantial way, but it essential to understand both as an education blockchain will have components of both because of the individual, institutional and government compliance utilization. In the Bitcoin public blockchain, the approval process is a very computer taxing operation (Vranken, 2017). First, when someone wants to send a document to another party, a block is created online to represent the transaction (Mustard and Davison, 2017). Once this happens the data is encrypted by a hashing algorithm (SHA-256) which transforms the data into a pile of jumbled digital information, called a hash code (Mustard and Davison, 2017). The hash code is essentially the blocks digital fingerprint, with the length of the hash code being 64 computer characters (Alcazar, 2017; Mustard and Davison, 2017). The hash code will always be 64 computer characters no matter if the transaction is for five or five-hundred units (Mustard and Davison, 2017). Once the transaction is hashed, it is than grouped together with other transactions into the block and is then ready to be validated (Murray, 2018). There are two main approval processes that are used in blockchain: proof-of-work and proof-of-stake.

Proof-of-stake protocols select miners to present blocks by allowing them to "stake" a portion of their data to the networks (Murray, 2018). This approval process works like a lottery system, where each transaction represents a lottery ticket (Murray, 2018). The protocol will randomly select a validator from the entire pool of staking and the winner is rewarded with the ability to place the next block in sequence 
(Murray, 2018). This approval process allows for a more stable network compared to the proof-of-work approval process

Proof-of-work, however, provides greater decentralization and liquidity than proof-of-stake because miners are constantly competing and incentivized to do so (Murray, 2018). Proof-of-work confirms transactions by having miners compete to solve mathematical equations to create new blocks and confirm transactions. Proof-of-work is the most common approval process (Murray, 2018). The miners are presented with several pieces of data, including the SHA-256 hash representing the previous block in the chain. They are also presented with details of the current transactions to be processed, such as the timestamp and other information applicable to the transactions. The miner's task is to then combine all this data into one hash and then produce what is known as a proof. This is accomplished by trial and error, as the miner can only determine the proof by trying all the possible permutations until an answer is found (Mustard and Davison, 2017).

No matter which approval process is used, once a block obtains enough confirmations, the transaction is validated and will be placed on the blockchain as the next sequential block (Murray, 2018). The network then proceeds to validate/confirm all the transactions of the block before it can be added to the ledger (Jernack, 2018). All blockchains have differing levels of confirmations (Murray, 2018). Once the new block is added to the blockchain, all miners (in both proof-of-work and proof-of-stake) receive a copy of the updated blockchain. This makes any discrepancies quickly evident and adds to the security of the blockchain (Mustard and Davison, 2017). Also, once a block is created and validated by the blockchain, it can never be destroyed or altered unless $51 \%$ of the blockchain agrees to do so (Murray, 2018). If a verifiable change were to take place, the change would be simultaneously registered on the ledger and would be viewable by all parties (Ray, 2018).

\section{BLOCKCHAIN TYPES}

The Bitcoin system is a public blockchain, but since its creation, many other types of blockchain have been created. The current blockchain systems are categorized in the following three main types: public, private, and consortium (Zheng et al., 2017). Figure 3 illustrates the characteristics of each type of blockchain.

FIGURE 3

\section{CHARACTERISTICS OF BLOCKCHAIN TYPES}

\begin{tabular}{|c|c|c|c|c|c|c|}
\hline \multirow{5}{*}{ 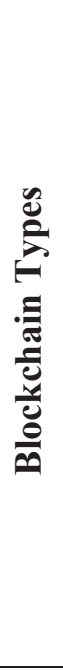 } & & & Read & Write & Commit & Example \\
\hline & \multirow{2}{*}{ ڤँ } & $\begin{array}{l}\text { Public } \\
\text { permissionless }\end{array}$ & Open to anyone & Anyone & Anyone & $\begin{array}{l}\text { Bitcoin, } \\
\text { Ethereum }\end{array}$ \\
\hline & & $\begin{array}{l}\text { Public } \\
\text { permissioned }\end{array}$ & Open to anyone & $\begin{array}{l}\text { Authorized } \\
\text { participants }\end{array}$ & $\begin{array}{l}\text { All or a subset } \\
\text { of authorized } \\
\text { participants }\end{array}$ & Sovrin \\
\hline & \multirow[b]{2}{*}{ 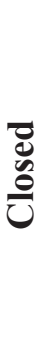 } & Consortium & $\begin{array}{l}\text { Restricted to an } \\
\text { authorized set of } \\
\text { participants }\end{array}$ & $\begin{array}{l}\text { Authorized } \\
\text { participants }\end{array}$ & $\begin{array}{l}\text { All or a subset } \\
\text { of authorized } \\
\text { participants }\end{array}$ & $\begin{array}{l}\text { Multiple banks } \\
\text { operating a } \\
\text { shared ledger } \\
\end{array}$ \\
\hline & & $\begin{array}{l}\text { Private } \\
\text { permissioned } \\
\text { ("enterprise") }\end{array}$ & $\begin{array}{l}\text { Fully private or } \\
\text { restricted to a } \\
\text { limited set of } \\
\text { authorized nodes }\end{array}$ & $\begin{array}{l}\text { Network } \\
\text { operator only }\end{array}$ & $\begin{array}{l}\text { Network } \\
\text { operator only }\end{array}$ & $\begin{array}{l}\text { Internal bank } \\
\text { ledger shared } \\
\text { between parent } \\
\text { company and } \\
\text { subsidiaries }\end{array}$ \\
\hline
\end{tabular}

Source: Hileman and Rauchs, 2017 
In a public blockchain all records are visible to the public and everyone can take part in the consensus process (Zheng et al., 2017). This is the most known example of blockchain because cryptocurrencies utilize this type of blockchain. There is, however, two types of public blockchains: public permissionless and public permissioned (Salmon and Myers, 2019). A public permissionless blockchain is the type of blockchain that is fully decentralized (Buterin, 2015). A public permissioned is open for anyone to view, but only authorized participants have access to write (i.e., generate transactions and send them to the network) and commit (i.e., update the state of the ledger) on the blockchain (Hileman and Rauchs, 2017).

A private blockchain, or permissioned blockchain, is one that only those nodes that come from one specific source are be allowed to join the consensus process (Zheng et al., 2017). In order to join a private blockchain network, individual participants must verify their identities, and be approved by the other members of the blockchain (Smith M., 2018). This type of blockchain is regarded as a centralized network since it is fully controlled by an organization with $51 \%$ ownership of the blocks that can alter the rules of the blockchain, revert transactions, modify balances, etc. (Zheng et al., 2017; Buterin, 2015). Thus, the permissions are kept centralized with one organization, but the ability to read the blockchain can be public or restricted to an arbitrary extent (Buterin, 2015). Since this type of blockchain is centralized, the approval process is also centralized.

The biggest advantage to a private blockchain's transactions is it is much cheaper to process than their public relative (Buterin, 2015). Setting up a smaller scale blockchain in the form of a private blockchain enables members of this network to save time and reduce the energy consumed to verify and process enabled transactions. This allows transactions and the organization to interact faster and at a reduced speed versus the public blockchain that requires extensive approval processes in the proof-ofwork and proof-of-stake models (Smith M., 2018).

With a private blockchain, the possibility of mistakes, collusion, and fraud lies with the owners of the blockchain. If an authorized person were to make an unauthorized file change that was accepted by the network, the blockchain would only log that a change occurred, not that it was an error (Ferris, 2019). Thus, the integrity of the blockchain needs to coincide with the integrity of the company, or person the company tasked with operating the blockchain. This is because a private blockchain can grant review rights to external entities if they deem that they do not have the resources or ability to do so themselves (Smith M., 2018).

A consortium blockchain is one that only a group of pre-selected nodes would participate in the consensus process (Zheng et al., 2017). This type of blockchain can be described as a mixture of the private and public blockchain. A consortium blockchain is constructed by several organizations, therefore; it is partially decentralized since only a small portion of nodes would be selected to determine the consensus (Zheng et al., 2017). An example is a group of financial institutions who operate a collective consortium blockchain. Each of the financial institutions operates a node of which a predetermined majority amount must sign the block for it to be valid. The right to read the blockchain may be public or restricted to the participants (Buterin, 2015). 
FIGURE 4

DIFFERENT TYPES OF BLOCKCHAIN PROPERTIES

\begin{tabular}{|l|l|l|l|}
\hline & Public Blockchain & $\begin{array}{l}\text { Consortim } \\
\text { Blockchain }\end{array}$ & Private Blockchain \\
\hline $\begin{array}{l}\text { Consensus } \\
\text { determination }\end{array}$ & All miners & One organization & Selected set ofnodes \\
\hline Read permission & Public & $\begin{array}{l}\text { Could be public or } \\
\text { restricted }\end{array}$ & $\begin{array}{l}\text { Could be public or } \\
\text { restricted }\end{array}$ \\
\hline Immutability & $\begin{array}{l}\text { Nearly impossible to } \\
\text { tamper }\end{array}$ & Could be tampered & Could be tampered \\
\hline Efficiency & Low & High & High \\
\hline Centralized & No & Yes & Partial \\
\hline Consensus process & Permissionless & Permissioned & Permissioned \\
\hline
\end{tabular}

Source: Buterin, 2015; Zheng et al., 2017

Figure 4 summarizes the three blockchain types and their different properties. This figure displays the different components of each type of blockchain in relation to the other types of blockchain. The figure shows how the private blockchain and public blockchain are essentially complete opposites, with the consortium blockchain in the middle leaning a little toward the private blockchain. Each of these types of blockchains have their good and bad properties that make them adaptable to specific industries.

\section{INDUSTRIES USING BLOCKCHAIN}

Blockchain is useful in situations where there is a desire to shrink the trust required between participants or where participants want to remove the necessity of having a trusted third party. For example, in 2016 alone, the global financial cost of fraud was estimated to be more than $\$ 4$ trillion (Hileman and Rauchs, 2017). The need to mitigate fraud is driving blockchain to be implemented by various industries. Fraud has been proved to be a financial burden on companies and many industries are presently implementing plans, if not already utilizing blockchain in their day-to-day operations. Currently the following industries are implementing some type of blockchain: the diamond industry, medical industry, retail, law offices, energy management, accounting, and education to a very small extent.

The diamond industry is using blockchain to track individual diamonds from mine to consumer, which would address counterfeiting, loss of revenue, insurance fraud, and conflict diamond detection. The medical industry is implementing blockchain to maintain a backup of person's DNA that can be readily and securely accessed for medical applications. Blockchain is being used in retail to record every action that happens in a retail supply chain and make all the data searchable in real time for consumers (Mustard and Davison, 2017). This transparency allows the consumer to scan a code on an item in the supermarket and know where the food was obtained, who certified it, where it was harvested or canned, etc. As mentioned earlier, Walmart is using the technology to ensure food processing safety (Smith S., 2018). In law offices and in the legal industry, blockchain has been used to secure videos or photographs so it is impossible to change one pixel without a record of the transaction (Guzzetta, 2018; Mustard and Davison, 2017). This is a major impediment to any attempt to falsify records in insurance claims or police footage.

Even in the energy management industry, blockchain is used to allow customers to buy and sell energy directly, without going through a central provider or broker (Mustard and Davison, 2017). Price Waterhouse Cooper, LLP has announced implementing a blockchain audit service. This would be used in all components of the audit procedure and change the audit protocol to not audit transactions but rather audit the blockchain where the transactions are filed (Coleman, 2018; Crosley and Anderson, 2018). 


\section{BLOCKCHAIN IN HIGHER EDUCATION}

Higher education is an industry where blockchain has not been implemented on a major scale. Conceivably, blockchain could transform the higher education and essentially disrupt its operations. With the unchangeable ledgers, security, transparency, and overall timesaving abilities blockchain offers, higher education's operating and record keeping functions could dramatically be changed as well as multiple administrative processes. The accessibility of these records, grades, assignments; advising students on which classes to take; certification verification; and essentially anything that deals with the student's or institution's transactions and records would transform the access, assessment, and security of an educational data base.

As mentioned before, the ideal higher education blockchain would be a consortium blockchain. The public blockchain would be too energy dependent with its approval process and a FERPA (Family Educational Rights and Privacy Act) violation would most likely occur with the blockchain viewable to anyone. The private blockchain could potentially work but having one node with the right to make any corrections is too centralized. The consortium blockchain would offer the best mixture of the decentralized public blockchain, while still staying compliant with FERPA regulations as the read permission would only be for those whose documents apply to the review (Olnes et al., 2017).

The advantage of using blockchain technology in higher education is the ability to accumulate large sets of data in perpetuity that are accurate, transparent and cannot be altered. The blockchain blocks would contain all the students' records whether they pertained to the students' admission process, completion of course work, certificates, lab academic work, submitted research papers, internship activities, publications, test data, quiz information as well as any other information associated with each class attempted much like current course digital record systems.

What is proposed is essentially an application where student can view anything, they need at any time needed. Students would log into the system with their email and password and review the database that lists each course they have been enrolled. They would then click on the course and view all completed assignments and view the associated grade. The blockchain would include papers, tests, and all assignments. The system validation would include an academic fraud verification to inhibit students from sharing old test information with others. This could be anything from not allowing the students to print test or sending an alert when an old test is opened.

Potential employers could request to view some of the data blocks. The student/alumni would submit an affirmation to allow the employer's access. This procedure allows the potential employer to know more about each job applicant. Imagine being able to see not only see an applicant's transcript, but the grades/evaluations earned. This would create a better understanding for employers filling entry level positions and help eliminate the liability of hiring an unqualified or inappropriate employee.

The blockchain also would help with the admission process. Rather than students eagerly waiting to hear back concerning their application to enroll at their school of choice, they could use the higher education blockchain (and the application) to upload the required documents and view the application process as it occurs.

For graduate students, the blockchain would not only include the admission documents, reference letters, admission test score but also the reference to the documents in the undergraduate blockchain data. The graduate student's blocks would be far more extensive to include publications, presentations, thesis and dissertation work in addition to commendations, honors or other associated information pertaining to the graduate students' academic performance.

\section{CONCLUSION}

The disruptive function of blockchain can have an impact on higher education processes, its administration and future employers. Blockchain is a sophisticated computerized process of data record keeping. The process is a sequential stepwise procedure to ensure secure documentation and confidentiality of the data which is expected by those completing higher education credentials. 
Based on current applications, Blockchain is good at what it does, it is transparent, and keeps permanent reports intact. Currently higher education records are kept as paper records or local databases which are not very efficient at sorting information, can get lost and are a premier target for hackers. Blockchain on the other hand, is a record sorting master that has a copy of every bit of data which is hard to alter giving it permanence and immutability. But best of all, a higher education open blockchain allows access to those seeking the information.

Blockchain provides a secure database for student test scores and data from online learning systems as it can track an immense amount of information. In addition to public information that is available to all, private information that should not be accessible can be held safe. Blockchain can provide the security for students, graduates, parents, teachers, higher education institutions, and industry. It provides a student/alumnus to become a lifelong registrar.

Blockchain provides an encrypted way of ensuring that a prospective employee, student or other applicant is qualified and educated to fill the requirements for a vacant position. That is, blockchain provides a secure means for all parties to prove their credentials enabling people to use their education as

a currency in the modern world. With the enhanced number of accredited education providers and a movement to skill-based national economy, blockchain provides a way for individuals to accumulate evidence of learning and achievement that cannot be violated or erased.

\section{REFERENCES}

Alcazar, V. (2017). Data you can trust: Blockchain technology. Air \& Space Power Journal, 31(2), 91101.

Barber, S., Boyen, X., Shi, E., \& Uzen, E. (2012). Bitter to better - How to make bitcoin a better currency. Financial Cryptography and Data Security, 399-414.

Buterin, V. (2015). On Public and Private Blockchains. Retrieved from https://blog.ethereum.org/2015/08/07/on-public-and-private-blockchains/

Coleman, L. (2018, March 17). Big Four Giant PwC Announces Blockchain Auditing Service. Retrieved March 14, 2019, from https://www.ccn.com/pwc-to-provide-audit-service-for-blockchain-tostimulate-adoption

Crosley, G., \& Anderson, A. (2018). The audit of the future: Daring, disruptive and data-driven but poised to add significant value to firms and clients. Public Accounting Report, XLII (2), 5-8.

Ferris, S. (2019). The blockchain brief. The Journal of Government Financial Management, 67(4), 24-29.

Grech, A., \& Camilleria. A. F. (2017). Blockchain in Education. Inamorato dos Santos, A. (ed.) EUR 28778 EN. doi:10.2760/60649

Guzzetta, J. W. (2018, March 1). How bitcoin works-A technological description of blockchain-based cryptocurrencies for nontechnical lawyers. Computer \& Internet Lawyer, 35(3), 21-23.

Hileman, G., \& Rauchs, M. (2017). Global blockchain benchmarking study. Centre for Alternative Finance. University of Cambridge. Cambridge, UK.

Jernack, A. (2018, July/August, 9). Blockchain and what it means in the accounting profession. New Jersey $C P A$.

Murray, J. (2018). The coming world of blockchain. The CPA Journal, June, 20-27

Mustard, S., \& Davison, M. (2017). Will blockchain technology disrupt the ICS world? In Tech, 64(6), 32-34.

Nakamoto, S. (2008, October 31). Bitcoin: A Peer-to-Peer Electronic Cash System. Retrieved from www.crypotovest.co.uk.

Olnes, S., Ubacht, J., \& Janssen, M. (2017, September). Blockchain in government: Benefits and implications of distributed ledger technology for information sharing. Government Information Quarterly, 34(3), 355-364.

Pelletier, S. (2018). Blockchain in higher education. The Chronicle of Higher Education, October.

Ray, S. (2018, March 26). Blockchains: The technology of transactions. Retrieved May 08, 2019, from https://Towardsdatascience.com/blockchains-the-technology-of-transactions-9d40e8e41216 
Salmon, J., \& Myers, G. (2019, January). Blockchain and associated legal issues for emerging markets. International Finance Corporation, 1-8.

Sharples, M., \& Domingue, J. (2016). The blockchain and kudos: A distributed system for educational record, reputation, and reward. Adaptive and Adaptable Learning, 490-496.

Smith, M. (2018). In wake of romaine E. coli Scare, Walmart deploys blockchain to track leafy greens. Retrieved January 24, 2019, from https://news.walmart.com/2018/09/24/in-wake-of-romaine-ecoli-scare-walmart-deploys-blockchain-to-track-leafy-greens

Smith, S. (2018). Blockchain augmented audit - Benefits and challenges for accounting professionals. The Journal of Theoretical Accounting Research, 14(1), 117-137.

Szydlo, M. (2004). Merkle tree traversal in log space and time. Advances in Cryptology - EUROCRYPT 2004 Lecture Notes in Computer Science, 541 - 554.

Tahmincioglu, E. (2018). Blockchain: Fraud or fortune? Directors and Boards, First Quarter, 21.

Vranken, H. (2017, October). Sustainability of bitcoin and blockchains. Current Opinion in Environmental Sustainability, 28, 1-9.

Wiatt, R. G. (2019). From the mainframe to the blockchain. Strategic Finance.

Zheng Z., Xie S., Dai H., Chen X., \& Wang H. (2017). An overview of blockchain technology: Architecture, consensus, and future trends. Proceedings of $6^{\text {th }}$ IEEE international Congress on Big Data 2017.557-564. 